information from the patient without success and that it would have been a grave error of judgement for him to attempt to force himself on a hostile, aggressive and uncooperative patient. This might have provoked a violent outburst against the psychiatrist or a member of the family by the patient who, particularly if psychotic, might also have become frightened and fled the house. It was thought appropriate for the psychiatrist to recommend admission under Section 26 of the Mental Health Act, which enabled the patient to be treated rather than simply observed, as would only have been permitted by Section 25 . Section 26 allowed compulsory detention for one year and could be reviewed and, if necessary, revoked-as subsequently occurred in this case.

The patient did not display psychotic symptoms on admission and a second consultant's opinion was obtained during the member's absence on leave. The second psychiatrist also felt that the patient should remain in a closed ward for further observations and when the member returned he agreed to the patient being discharged when appropriate arrangements had been made for him.

\section{The trial}

The case came to trial in October 1986 and lasted 10 days. Unusually in a civil claim the plaintiff elected for trial by jury. This was possible because the action included a claim for damages for false imprisonment. The doctors and the plaintiff were questioned carefully and experts on each side gave their opinion. At the end of the case four questions were put to the jury by the judge:
1. Was the plaintiff mentally ill within the meaning of Section 26 of the Mental Health Act 1959 when he was admitted to hospital?

2. Did the psychiatrist fail to exercise reasonable care in making his recommendation?

3. Did the GP fail to exercise reasonable care?

4. If either of the defendants failed to exercise reasonable care what sum would the jury award by way of (a) damages and (b) aggravated damages (if any).

The jury retired for over three hours and returned their verdict:

1. No, the patient was not mentally ill.

2. No, the psychiatrist was not negligent.

3. No, the GP was not negligent.

Judgement was accordingly entered for the defendants with costs against the plaintiff. Unfortunately these costs could not be enforced without the leave of the court, and the MDU could not recover the considerable expense of defending its members.

Both doctors expressed their gratitude and relief at the end of the trial. The GP said that he hoped to get his life back to normal as quickly as possible as the case had been hanging over his head for more than five years.

This article first appeared in the Spring 1987 issue of the Journal of the Medical Defence Union and is reproduced by kind permission of The Medical Defence Union.

\title{
Serious Head Injuries
}

The National Head Injuries Association, 'Headway', is a registered charitable trust which has been formed to provide advice and help to relatives of patients with serious head injuries. With the co-operation of hospital consultants and staff, medical social workers, relatives of patients and patients themselves, groups are already meeting here and abroad, and new groups are being formed. The main aims of these groups are to give support alongside medical staff in hospital through counselling, to lessen the sudden trauma of having a seriously head injured relative and to offer activities, independently or in a group, to help rehabilitate the patient at home, as well as providing social and other activities for the long-term handicapped.
'Headway' aims to act as a liaison body between all local groups and to encourage groups to start in areas where they do not exist. It will encourage the development of mechanical, electronic and other aids not otherwise available. It also hopes to promote specialist services for assessment and training facilities, to provide short-term holiday care for patients and long-term care when this becomes essential, and to facilitate the provision of suitable housing for independent living. Further information is available from the National Head Injuries Association, 17-21 Clumber Avenue, Sherwood Rise, Nottingham NG5 IAG (telephone 0602 622382). 